\title{
Alcoholism among Youth: A Case Study in Kuala Lumpur, Malaysia
}

\author{
Mohd Ramlan Mohd Arshad, Munirah Omar, and Nurul Afiqah Shahdan
}

\begin{abstract}
The growing numbers of social problems among youth have become the major fear of the government agencies. Alcoholism among youth is one of the primary topics discussed when studying subject regarding social problems. The seriousness of alcohol consumption leads to the urgencies for researchers to examine the elements that encourage such scenario happened. Thus, this paper aims to explore the various factors that lead to alcohol consumption among youth. Methodologically; the paper employs a quantitative approach to have in depth understanding of the antecedents that lead to the issue. It begins with an introductory background of alcoholism among youth and the scenario of alcoholism among youth in Malaysia as in general. The paper then proceeds to capture the factors that lead youth to consume alcohol exaggeratedly. The analysis provides the factors that lead to alcohol consumption, the frequencies of consumption, starting age of youth to consume alcohol and also correlation analysis on the subject matter. There also some discussion and suggestions on alcoholism among youth.
\end{abstract}

Index Terms-Alcoholism, youth, social issue.

\section{INTRODUCTION}

Nowadays, it can be determined that the social issues among youth have become the major problem and concern of the country. The social issue discusses here is concentrating more on the alcoholism among youth. There are many reasons and factors that lead to the alcoholism and this issue will lead to the undesirable effects and impacts to an individual, economy and society as a whole. Underage drinking varies by geographic region since 2002 and it has been more eminent in the Northwest (31.4\%) and Midwest (31.0\%) than the South (26.4\%) and West (26.0\%) [1]. Generally, it has been found out that men are more likely to drink than women with the estimate of $68 \%$ for men and $54 \%$ for women and men also drink more frequently than women [2].

Intoxicant is a worldwide social and medical problem. Over the past four decades alcohol consumption has increased in quantity and frequency. The age at which people initiate consuming alcohol has also declined [3]. Unipolar major depression, alcohol abuse, bipolar affective disorder (manic-depression), schizophrenia and obsessive-compulsive disorder are among the 10 leading causes of disability worldwide since 1990 [4]. In a study conducted by

Manuscript received January 19, 2015; revised June 10, 2015.

The authors are with the Faculty of Administrative Science and Policy Studies, Universiti Teknologi MARA Malaysia (e-mail: ramlanarshad@gmail.com,

Nurulafiqahsahdan@yahoo.com).
Hamalainen et al. [5] it was established that alcohol consumption was an important risk factor for major depressive episode. Adolescents often indulge in alcohol consumption either on peer pressure or for enjoyment [6], [7]. Alcohol use during late childhood and adolescence can lead to poor performances in academics, as well as social and emotional disturbances and often leads to high risk behavior and impairment in psychosocial development [6]-[8].

Malaysia is the tenth largest consumer of alcohol in the world and so few studies have been carried out to find the precise magnitude of the problems caused by this consumption [9]. The facts and figures show that it is increasing each year. The taxes on alcohol beverages collected for the year 1996 rose to RM817 million from 769 million in 1994. Similarly, in 1995 there were 2,360 public premises licensed to sell alcoholic drinks [9]. In 1996, this number has doubled. Each year, Malaysians spend over RM 2 billion on alcohol in the form of beer and cheap spirits known locally as Samson [9]. Alcoholic drinks are easily available in coffee shops, supermarkets, sundry shops and plantations, together with aggressive advertising and promotions are driving more Malaysians to drink. Its effect on Malaysian society can be seen directly in the number of fatal accidents due to drunk driving or indirectly in the psychological effects on family members of alcoholics [9].

Among youth, it has been found out that the young people drink less frequently than older people. However, young people are more likely to exceed the daily benchmarks where, $36 \%$ of men aged 16-24 had drunk more than 4 units on at least one day compared with $20 \%$ of men aged 65 and over [10]. Among young women, 37\% of those aged 16-24 had exceeded 3 units on at least one day compared with only $11 \%$ of those aged 65 and over [10]. According to Sommers and Sundararaman [11], underage drinking varies by geographic region since 2002 and it has been higher in the Northwest (31.4\%) and Midwest (31.0\%) than the South (26.4\%) and West $(26.0 \%)$.

The World Health Survey shows abstinence rates among 18-24 year olds to range from $6.7 \%$ in Latvia to $98.6 \%$ in the Comoros, with the percentage of heavy episodic drinkers ranging from $0.2 \%$ in Lebanon and Malaysia to $20.1 \%$ in the Czech Republic. Particularly in the WHO European Region and the WHO Region of the Americas, young adults (aged 18-24) are more likely to engage in heavy episodic drinking than the general adult population for examples are Brazil, Czech Republic, Spain, Dominican Republic [12]. According to Kortteinen [13], $45 \%$ of Malaysians youths admitting to consume alcoholic drinks are underage. 


\section{BACKGROUND}

\section{A. Problem Statement}

Due to the reason that alcohol may harm the adolescent brain, individuals who start drinking before the age of 15 are five times more likely to have alcohol-related problems later in life [13]. In the United States, people in the age $12-20$ drink almost $20 \%$ of alcohol consumed, although drinking by persons under the age of 21 is illegal in all states [13]. Each year, approximately 5000 young people under the age of 21 die as a result of underage drinking [13]. There are several effects that resulted from the consumption of alcohol among youth. For the underage students who drink alcohol, it can be seen that it is commonly resulted in the low educational achievement and high absenteeism rates [13]. In the United States, it has been reported that medical care, work loss and pain, suffering directly associated with underage drinking costs $\$ 2,207$ annually for each young person in that country [13].

In Malaysia, the legal age for alcohol consumption is 21 for non-Muslims [14]. For Muslims, there is no legal drinking age as it is against the law for them to consume these beverages [14]. $45 \%$ of Malaysians youths admitting to consume alcoholic drinks are underage [14]. Most Muslims abstain from alcohol because it is forbidden by their religion as it is illegal to sell and buy alcohol for a Muslim. This has raised a problem in Malaysia. People who drink alcohol during adolescents may develop problems related to normal development [14]. It is not necessary for people to drink because it can cause damage to their mental and physical health [14]. During this stage of life the brain and mind are going through an important stage of development and alcohol can interfere with that [14]. Besides, drinking alcohol may lead people perform badly in school or college [14]. This may have a negative impact on their future opportunities in life [14]. Furthermore, it can encourage youths to engage in vandalism or other criminal acts [14]. It can mean that young people become sexually active [14]. Those individuals who drink at a young age are more likely to try other drugs [14]. This means that such individuals could be on a path to the hell of lifelong drug addiction [14]. Therefore, this research is conducted in order to study the contributing factors and the effects of alcoholism among youth.

\section{B. Significance of the Study}

As known, heavy alcohol consumption will lead to further social problems such as vandalism, bully, sexual assault and suicide. Therefore, by educating the public and youth regarding the negative impact of the alcoholism will also help in the effort of reducing the social problems that might occur when consuming alcohol.

Public and youth often ignore the fact that consuming alcohol will contribute in many undesirable effects. This is due to the reason that they are not well educated about this. Educating the public and youth about the consequences of alcoholism will help in encouraging them to avoid the alcohol consumption in the first place.

\section{LITERATURE REVIEW}

Alcohol which is also known as ethanol or ethyl alcohol is the ingredient found in beer, wine and spirits which causes drunkenness [15]. Alcoholism is characterized by craving, tolerance, a preoccupation with alcohol and continued drinking even though people know about its harmful consequences such as liver disease or depression caused by drinking, which it means that an urge to drink and to continue to drink despite of the fact that drinking sustains substantial damage to their health and personal or business affairs [16]. What is counted as a drink? In the United States, a "standard" drink is any drink that contains about 0.6 fluid ounces or 14 grams of "pure" alcohol and even moderate levels of drink which is up to 2 drinks per day for men or 1 for women can be too much in some circumstances such as taking medications that interact with alcohol or pregnant or trying to become pregnant [17].

For some people, it takes quite a few drinks to get a buzz or feel relaxed and they tend to drink more, socialize with people who drink a lot, and develop a tolerance to alcohol and as a result, they have an increased risk for developing alcoholism [17]. The higher alcohol levels can also cause liver, heart, and brain damage that can go unnoticed until it's too late and all drinkers need to be aware that even moderate amounts of alcohol can significantly impair driving performance, even when they don't feel a buzz from drinking [17]. Alcoholism is defined in Webster's Ninth New Collegiate Dictionary as a continued excessive or compulsive use of alcoholic drinks which is associated with excessive and usually compulsive drinking. Alcohol abuse refers to the misuse of alcohol resulting in problems to the abuser and those he or she may affect and alcoholism involves developing a dependency on alcohol [18].

Dr. James Royce defines alcoholism as "a chronic illness or disorder characterized by some loss of control over drinking, with habituation or addiction to the drug alcohol, or causing interference in any major life function such as health, job, family, friends or the law (Alcohol Problems and Alcoholism, page 10). There are four phases of alcoholism, which are social drinking, seeking the mood change, and constantly seeking the mood change and addiction. Social drinking suggests drinking for stress relief, which results in mood change which it may begin as a result of peer pressure, to go along with the crowd or to alleviate boredom or stress [19]. Seeking the Mood Change on the other hand leads to drinking for the purpose of achieving mood change which drinking habits begin to fall into personal patterns such as certain times of the day [19]. Constantly Seeking the Mood Change is the phase 3 that involves a regular pattern of drinking for the desire effects and this may take the form of regular, ongoing daily drinking or sporadic episodes of drunkenness followed by periods of abstinence which is often labeled as "periodic drinking" [19]. The last phase is addiction, which is the situation whereby the cells of the alcoholic's body adapt rapidly to the increasing ingestion of alcohol, resulting in a higher level of "tolerance" [19]. This means the person is able to consume more beverage alcohol without obvious physical effects or showing signs of impaired behavior and increased tolerance also demands that the person must drink more to achieve the effects mentioned in stage 1 [19]. The nervous system adapts to the escalating level of alcohol, resulting in physical dependence which drinking beyond tolerance level 
results in drunkenness and suddenly, drinking less than the tolerance level throws the cells of the body into acute distress, hence the growing need for alcohol becomes the focus of the victim's life [19].

It has been found out that there are several effects that can occur as a result of alcohol consumption among youth. Firstly, alcohol consumption will affect the health of those consumers Wechsler and Nelson [20] propose four main categories resulted from the alcohol consumption. There are problems with the academic performances, social relationships, risk-taking behaviors and health [21]. According to Sommers \& Sundararaman [22], [11], it is stated that alcohol consumption among person under the age of 21 has been identified as a major public health problem. Minors who drink are more likely to commit suicide, break the laws, or be the victims of violence. Alcohol is seen as the reason of almost one-third of youth traffic fatalities. In 2004, there were more than 142,000 emergency rooms were visited by youth from the age of 12-20. This is as a result of injuries and other conditions linked to the consumption of alcohol. It was reported that approximately 5000 young people under the age of 21 die each year due to underage drinking.

On the other hand, medical care, work loss and pain and suffering directly associated with underage drinking costs $\$ 2,207$ annually for each young person in the United States. Alcohol Advisory Council of New Zealand [23] stated that there are immediate and long-term effects of alcohol consumption on the health. Immediate effects of alcohol use are that it will cause many different types of injuries, including injuries from road traffic accidents, assaults and falls. This is usually because alcohol impairs the brain's thought processes and the coordination of muscles, causing clumsiness and difficulty in walking. Common injuries are seen in the emergency department include cuts, bruises, sprains and broken bones. Long-term effect of alcohol use on the other hand is that moderate alcohol use may protect against thinning of the bones, which makes the bones more likely to break. However, chronic heavy alcohol use interferes with the absorption of calcium and bone formation and can actually lead to thinning of the bones. Chronic heavy use is also associated with a painful condition where bone tissue dies [23].

As in the case of youth, young people up to the age of 25 years are at a higher risk of harm from alcohol use than older adults [24] This is because young adults have the greatest risk of injury and accidents related to alcohol use, an increased risk of alcohol dependence and a lower tolerance to alcohol than older adults. According to Faculty of Public Health [24], alcohol-related events include accidents and injuries as well as an estimated 1,000 suicides per year in England alone. It is estimated that $70 \%$ of admissions to accident and emergency departments at peak times are alcohol-related. Other chronic conditions as a result of alcohol consumption are obesity, high blood pressure, coronary heart disease, pancreatitis and mental health problems such as depression and alcohol dependency [25]. Alcohol also increases the risk of developing certain cancers including liver, mouth, oesophagus, pharynx and breast and bowel and colorectal cancer. Studies consistently show that alcohol increases the risk of cancer and 20 percent of alcohol related-deaths are due to cancer, such as cancer of the mouth, liver and breast [25].

The World Health Organization defines violence as "The intentional use of physical force or power, threatened or actual, against oneself, another person, or against a group or community that either results in, or has a high likelihood of resulting in, injury, death, psychological harm, or deprivation"[26]. Youth that involved in the alcohol consumption often has problems with the social integration, are more prone to fighting and are more often resisted to participate in healthier activities. It is stated that, the youth has a higher risk of being involved in illegal activities and participating in unprotected sex [27]. By referring to Siemieniako \& Kubacki [28], part of the growing problem with increasing alcohol consumption among women might lead to unfeminine and immoral behaviors. World Health Organization [28] stated that alcohol uses are risk factors for both being victimized and performing youth violence. Youth violence can be in many forms. These include bullying, gang violence, sexual aggression and assaults. Youth violence normally occurs on the streets, bars and nightclubs. Consuming alcohol will directly affect the cognitive and physical functions that can reduce the self-control and the ability to process incoming information and assess risks.

Alcohol is believed to facilitate aggression by increasing confidence and willingness to take risks and reduce the ability to consider the consequences of their behavior [29]. Other than that, reduced physical control in potential dangerous situations will make some drinkers as the easy targets for perpetrators [29]. Normally, crowded and poorly managed drinking venues will contribute in the increased aggression among drinkers. Males are more likely to be both perpetrators and victims of youth violence as compared to females [30]. The example of alcohol-related violence in bars and clubs often due to events such as spilt drink or an advance by one person towards another's sexual partner and these will later affect the health and well-being of the victims [30]. Alcohol consumption is a prominent feature of many types of violence [30]. These include violence at the public setting, sexual violence and domestic violence.

In England, alcohol is thought to play a part in approximately in 1.2 million violent incidents. It is supported that, alcohol consumption increases the risk of being a victim of violence through the decrement of physical capacity. It also increases the likelihood of perpetrating violence through increased aggression [31]. It is stated that consumption of alcohol increases the likelihood that a person will be both the victim and perpetrator of social disorder. $68.1 \%$ of persons who committed verbal abuse were also victims of verbal abuse. Aggression may be a cause of increased alcohol consumption [31]. According to "selective disinhibition theory," alcohol's well known negative effects on people's perception, ability to interpret others' actions, intentions and judgment, interact with a complex set of social and psychological circumstances to result in violence in certain situations. Alcohol tends to lower people's inhibitions against using violence to achieve their goals [32]. In a 2003 study of Otago University students aged 16 to 24 years, it was shown that $84 \%$ of those surveyed had experienced negative effects from other students' drinking [32].

The study showed that $10 \%$ of the women and $20 \%$ of the 
men were assaulted at least once in the four weeks preceding the survey, and one fifth of the students had their property damaged [33]. Alcohol is also a significant contributory factor to violent crime -which $44 \%$ of victims of violence in England and Wales believed their attacker to be under the influence of alcohol and it is thought to be a factor in at least half of all domestic violence incidents in the UK [33].

According to Alcohol Advisory Council of New Zealand [34], the effects of alcohol are more vulnerable to the negative impacts on memory and learning, as the brain is still developing up until the 20s. The most obvious mechanism by which drinking may affect GPA is through the allocation of time to study, which it means that, since drinking and studying take time, drinking may reduce the number of hours that a student spends studying outside of class and hence reduce their level of academic achievement [34]. The consumption of alcohol can be expected to have a negative impact on schooling both directly through its potential impact on cognitive ability and indirectly through its impact on study habits [35]. For the underage students who drink alcohol, it can be seen that it is commonly resulted in the low educational achievement and high absenteeism rates [35].

Yamada et al. [36] find that both the number of drinks consumed during the past week and being a frequent drinker significantly reduces the probability of high school graduation, which a $10 \%$ increase the probability of being a frequent drinker is found to reduce the likelihood of graduation by $6.5 \%$. There is evidence exists on the direct effect of drinking on cognitive ability. Based on clinical studies, Nordby et al. [37] showed that drinking reduces recall, which can be expected to have a direct effect on the educational performance of the students. Alcohol consumption will affect the education performance of students in numbers of ways. The first is focused on the negative impacts on the class attendance. According to Wechsler et al. [38], frequent binge drinkers are more likely to miss a class and fall behind in their schoolwork. Other research stated that the number of drinks consumed correlates positively with the number of classed missed [38]. To support this, Wyatt [39] stated that frequency of alcohol consumption was associated positively with absenteeism from classes disliked. The second effect of alcohol on education performance is focusing on the negative impacts on time spent studying. Wolaver [40] stated that alcohol consumption has a negative predictive effect on study hours under all definitions of drinking, which are binge, frequent binge, drunkenness and frequent drunkenness. This means that more frequent use of alcohol usually produces larger negative effects on study hours, with frequent drunkenness having the largest negative effect [40]. To support this, it has been found that there is a positive relationship between heavy episodic alcohol use and the time students spend on academics [40]. The probability of getting a high GPA significantly decreases as the frequency of heavy episodic drinking increases [40]. The third effect of alcohol on education performance is determined by the grade point average, where it is found out that binge drinking two or more times in a typical two week period is linked to significantly lower semester grades [40]. Preseley [41] stated that the heaviest drinkers obtain the lowest grades. The amount of alcohol consumed correlates significantly with GPA [41].
Heavy college drinking predicts a reduction in the probability of having an "A" average cumulative GPA [41]. There is a significant relationship between GPA and the percent of students who drink or are heavy drinkers [41] and to support this, there is a significant decline in GPA when comparing abstainers to heavier drinking categories as stated by Rau \& Durand [41]. This means that the heaviest drinkers make the lowest grades.

\section{Methodology}

\section{A. Research Design}

Research design is a plan and research structure that could assist the researcher to answer the questions explored in the research. A design is used to structure the research, to show how all the major functions of the research project (e.g., the sample or groups, measures, treatment or programs, and method of assignment) work together to attempt in addressing the fundamental research question [41]. With regards to the facts, research design employed was cross-sectional cum correlation design. The research required specific information from the youth in Kuala Lumpur, Malaysia thus the use of the questionnaire is to ensure the standardized gathering data.

The unit of analysis refers to the level of aggregation of the data collected during the data analysis stage. In dealing with this research, individuals will be used as the unit of analysis. Questionnaires are distributed to the people who involved in alcoholism in the Kuala Lumpur area using snowball sampling to obtain their opinion and view about the factors that can then lead to alcoholism among youth.

\section{B. Sampling Technique and Sample Size}

One hundred and fifty (150) youth age range from 15 to 24 stayed in Kuala Lumpur are the sample size for this inquiry. The sampling technique is nonprobability samples which are snowball technique.

Snowball sampling applies in the cases whereby the units are not easily identified. People may seem do not want to be known. In these cases, the research will seek out one or more respondents and discreetly develop further units from the surveyed units.

\section{DATA Collection AND ANALySES}

The primary data for this study came from the completed questionnaires administered to the respondents by the researchers. This questionnaire is divided into six parts which are, part A is on Respondents' Demographic Profiles; Part B focused on the interpersonal and alcoholism, part $C$ focused on the availability of alcohol products and part $\mathrm{D}$ focused on poor knowledge that lead to alcoholism among youth, while in Part E concentrate on the subject of alcoholism. In part B to part $\mathrm{E}$, the respondent requested to indicate on 1 to 5 which is (1= Strongly Disagree, $2=$ Disagree, $3=$ Neutral, 4= Agree, $5=$ Strongly Agree).

Depending on the research questions and hypotheses, parametric analyses were carried out accordingly. For the first part of the questionnaire, the demographic variables require descriptive statistics, but for the independent and dependent 
variables were measured by a scale of one to five, correlation analyses were undertaken. Lastly, it is important to note that a pilot study was conducted to ascertain the reliability and validity of the instrument where the Cronbach's Alpha Reliability Statistic Test returned a score of above 0.71 denoting that the assertions in the questionnaire are true and valid.

\section{FINDINGS}

TABLE I: PROFILE OF RESPONDENTS

\begin{tabular}{l|lll}
\hline Characteristics & Details & Frequency & Percentage (\%) \\
\hline Gender & Male & 74 & 49.3 \\
Age & Female & 76 & 50.7 \\
& $18-20$ & 21 & 14.0 \\
Race & $21-23$ & 103 & 68.7 \\
& $24-26$ & 26 & 17.3 \\
& Malay & 101 & 67.3 \\
& Chinese & 27 & 18.0 \\
& Indian & 22 & 14.7 \\
\hline
\end{tabular}

Table I indicates the majority of the respondent is female with the percentage of $50.7 \%$ as compared to the male respondent which is $49.3 \%$. In the section of age, $14 \%$ of them are from the age of 18 to $20,68.7 \%$ of them are from the age of 21 to 23 and lastly $17.3 \%$ of them are from the age of 24 to 26. It has been found out that the majority of the respondent is Malay with the percentage of $67.3 \%$. $18.0 \%$ of them are Chinese and $14.7 \%$ of them are Indian.

\begin{tabular}{c|ll} 
TABLE II: YOUTH'S AGE AND CONSUMPTION LEVEL \\
\hline Age & Frequency & Percent $(\%)$ \\
\hline 15 & 2 & 1.3 \\
16 & 14 & 9.3 \\
17 & 42 & 28.0 \\
18 & 30 & 20.0 \\
19 & 25 & 16.7 \\
20 & 25 & 16.7 \\
21 & 7 & 4.7 \\
22 & 2 & 1.3 \\
23 & 1 & .7 \\
24 & 2 & 1.3 \\
Total & 150 & 100.0 \\
\hline
\end{tabular}

Table II above indicates that the majority of the respondent started drinking alcohol at the age of 17 with the percentage of $28 \%$. While $20 \%$ of respondents started to drink at the age of 18. At the age of 19 and 20 , its share same percentage which is $16.7 \%$. The least number of respondents who started to drink is at the age of 23. This is worrying statistic, as in Malaysia at the age of seventeen, the youths are at the level of secondary school which will sit for Malaysia Education Certificate exam.

From the Table III below, it indicates that most of respondents drink because of they want to try something new to them. With the higher number of percentage, $39.3 \%$ with the reason of trying. Followed by 14\%, respondent tends to drink because of their family. This is because their family consumed alcohol and makes them to follow what their family did. Next percentage is $20 \%$ where respondents started to drink because want to have fun. Besides that, some of the respondents started to drink due to stress. By taking alcohol, they believe it will reduce the stress condition; however, this assumption is violating the medical facts. Friends also are the reason of the respondents to start drinking with the number of percentage, $15 \%$.

TABLE III: FACTORS LEAD TO ALCOHOL CONSUMPTION

\begin{tabular}{|l|l|l|}
\hline Reasons & Frequency & Percent $(\%)$ \\
\hline Culture & 2 & 1.3 \\
\hline Enjoy & 1 & .7 \\
\hline Family & 21 & 14.0 \\
\hline Fun & 15 & 10.0 \\
\hline Habit & 4 & 13.3 \\
\hline Happy & 1 & 2.7 \\
\hline Myself & 1 & .7 \\
\hline Occasion & 1 & .7 \\
\hline Party & 6 & .7 \\
\hline Pleasure & 1 & 4.0 \\
\hline Stress & 16 & .7 \\
\hline Try & 59 & 10.7 \\
\hline Work & 2 & 39.3 \\
\hline Total & 150 & 1.3 \\
\hline
\end{tabular}

TABLE IV: FREQUENT OF CONSUMPTION

\begin{tabular}{|l|l|l|}
\hline & Frequency & Percent $(\%)$ \\
\hline Everyday & 2 & 1.3 \\
\hline 3-5 times a week & 17 & 11.3 \\
\hline once a week & 32 & 21.3 \\
\hline only on weekends & 38 & 25.3 \\
\hline only on special occasion & 61 & 40.7 \\
\hline Total & 150 & 100.0 \\
\hline
\end{tabular}

On the above Table IV shows that most of respondents drink during special occasion with the percentage of $40.7 \%$, $25.3 \%$ of them drink only on weekends, $21.3 \%$ of them once a week, $11.3 \%$ of them drink for three to five times a week and $1.3 \%$ of them drink everyday.

TABLE V: CORRELATIONAL ANALYSIS

\begin{tabular}{|l|l|l|l|l|}
\hline Variables & DV & $\mathbf{1}$ & $\mathbf{2}$ & $\mathbf{3}$ \\
\hline $\begin{array}{l}\text { Alcholism } \\
\text { among Youth }\end{array}$ & - & & & \\
\hline $\begin{array}{l}\text { Interpersonal } \\
\text { Problem }\end{array}$ & $0.143^{*}$ & - & & \\
\hline $\begin{array}{l}\text { Alcohol } \\
\text { Availability }\end{array}$ & $0.222^{* *}$ & $0.161^{*}$ & - & \\
\hline $\begin{array}{l}\text { Knowledge of } \\
\text { Alcoholism }\end{array}$ & $0.187^{*}$ & $0.163^{*}$ & 0.126 & - \\
\hline
\end{tabular}

H1: There is a significant relationship between 
interpersonal problems and alcoholism among the youth.

$\mathrm{H} 2$ : There is a significant relationship between the availability of alcohol and alcoholism among the youth.

H3: There is a significant relationship between poor or lack of knowledge of alcoholism and alcoholism among the youth.

Based on the Table $\mathrm{V}$ above, it shows that hypothesis $\mathrm{H} 1$ is accepted $(r=.143, p<0.05)$. Therefore, there is a significant positive relationship between interpersonal problems and alcoholism among the youth. It was hypothesized that higher interpersonal problems resulted in the alcoholism among youth. It also shows that hypothesis $\mathrm{H} 2$ also accepted ( $r=.222$, $p<0.05)$ where there is a significant positive relationship between the availability of alcohol and alcoholism among the youth. It was hypothesized that higher availability of alcohol resulted in the alcoholism among youth. Lastly, the table shows there is a relationship between poor knowledge and alcoholism with, $r=187, p<0.05$. Therefore, there is a significant positive relationship between poor or lack of knowledge of alcoholism and alcoholism among the youth.

\section{DISCUSSION}

From the result shown, it can be seen that, the significance in correlation with the dependent variable is 0.041 which is less than 0.05 of the significance value. It means that the interpersonal problems can influence the youth to involve in the alcoholism. The findings also indicated that there is a significant positive relationship between the availability of alcohol as an influencing factor that leads the alcoholism among youth. It means that the availability of alcohol can influence the youth to involve in the alcoholism. It is also can be seen in the findings that there is a significant positive relationship in the lack of knowledge of alcoholism as an influencing factor in leading the alcoholism among youth that lives in Kuala Lumpur.

Thus, the results supported by the several previous literatures on alcoholism among youth. Based on the interpersonal problems, Johnston and O'Malley [42] stated that youth drank because of boredom or because alcohol helped them to escape their problems. In the article of "Alcohol use among adolescents," a study explored the reasons why so many young people drink alcohol because the pleasurable aspects of drinking. For the second factor, the availability of alcohol, it is supported by some experimental studies conducted in laboratory conditions have indicated that showing televised alcohol advertisements to individuals can raise their short term interest in alcohol consumption as tested virtually immediately after advertising exposure, when alcohol is made available, compared to matched individuals who were not exposed to any alcohol advertising [42]. Lastly is supported by Johnston and O'Malley [42] said lack of parental education was associated with increased rates of alcohol use and being drunk. Health literacy is vital for people to gain access to, understand and use information [43]. This is an evidence shows that there is positive relationship between lack or poor of knowledge towards alcoholism.

The availability of alcohol is the main factor contributes youth to alcoholism compared to poor and lack of knowledge.
It is also can be seen that the respondents prefer to drink alcohol because of the physical availability; it is convenient to obtain alcohol for drinking purposes. Moreover, physical availability also includes regulations and policies. Government is responsible in setting up the national alcohol policies, for example the limit age for buying alcohol. When there is no limitation, it makes the youth to drink alcohol as it is very convenient to get. There is evidence, when Finland allowed the sale of medium beer (alcohol content at most $4.7 \%$ ) in grocery stores in 1969, the total alcohol consumption rose nearly $50 \%$ in a year [43]. It can be supported from the Faculty of Public Health [43] finding that lack of national policies will increase the number of alcoholism among youth. There is existing evidence stated that it is fairly strong that off premise state monopolies limit both alcohol consumption and related problems, and that abolishing monopolies can increase alcohol consumption.

Besides that, the advertisement is also the factor of youth to drink alcohol. It is can be supported by Kohn and Smart [43], indicated that showing televised alcohol advertisements to individuals can raise their short term interest in alcohol consumption as tested virtually immediately after advertising exposure, when alcohol is made available, compared to matched individuals who were not exposed to any alcohol advertising.

\section{CONCLUSION}

As a conclusion, there are several factors that lead to alcoholism among the youth that lives in Kuala Lumpur as had been identified in the study, which are interpersonal problems, availability of alcohol and poor and lack of knowledge on alcoholism. The findings have shown that among the three independent variables, the availability of alcohol became the most influencing factor in leading the youth to involve in the alcoholism. In simple words, the availability of alcohol is the main reason why the respondents involve in the alcoholism. Most of the respondents feel that they need to try drinking the alcohol as alcohol has been made available in the country. Other factors also have shown their own contribution in becoming the factors that lead to alcoholism among the youth. The respondents agreed that the lacking in the knowledge of the bad effects that the alcohol and also lack of religious knowledge will lead to alcoholism among the youth. They also agreed that having interpersonal problems such a family disharmony, pressure and friends' influences can lead to alcoholism among the youth that lives in Kuala Lumpur. By having such information, it is hoped that it will help the authorities in deriving better policies in youth development to eradicate alcoholism among youth in Malaysia

\section{RECOMMENDATION}

Government needs to review back the national policies on alcohol. Government plays an important institution in ensuring the policies become effective. First and foremost, government needs to impose heavier taxes on alcohol. The primary reasons for increasing excise taxes on alcohol are 
correct for the external costs associated with alcohol consumption and to raise revenues for programs aimed at reducing the social burden of alcohol misuse. Price also will influence the behavior of heavy drinkers and that young drinkers are especially responsive to price. Increases in alcohol taxes are associated with reductions in motor vehicle fatalities, crime, industrial injuries and dropping out of school. The effectiveness of policy changes in this area depends on government oversight and control of alcohol production and distribution. Second is the government needs to enforce the use of beer licenses and making regular spot checks on premises selling alcohol. Government should regularly make spot checks on the premises. If the premises break the rules and regulations, government should suspend their license. Besides, the government should restrict on hours and days of selling alcohol. Having reduced hours and days of sale of alcohol can reduce alcohol consumption and problem levels, with the effects concentrated during the time of closure.

One of the factors that lead to alcoholism among the youth that lives in Kuala Lumpur is the lack and poor of knowledge on the alcoholism itself. By having no knowledge or poor knowledge of the dangers that alcohol consumption will bring, people, especially youth will drink alcohol without having the fear of the harm that alcohol can do to them. The poor of knowledge of alcoholism are usually as a result of lacking in the exposure of the dangers and effects of the alcohol itself to the youth. Therefore, as the recommendation, it is important for the responsible body, such as the Health Ministry to take an effort in implementing various of education programs on the dangers of alcohol in order to increase the awareness of the public especially youth on the bad impacts of alcohol. The educational programs that are to be implemented should be able to install the knowledge intended to be delivered to the youth, hence, can reduce or prevent alcohol consumption among the youth. The education programs on the dangers of alcohol should be implemented at various levels and place. This is as to increase the effort to make the youth know and more aware about the problems that are about to deal with when they consume alcohol and involve in alcoholism. The education programs on the danger of alcohol should be implemented in school as education at an early stage is very important. Other than that, a campaign involving the public can be implemented and electronic media can be used in order to help in transmitting the message of the dangers that alcoholism will bring and in the end reduce the alcohol consumption among youth.

\section{ACKNOWLEDGMENT}

We like to thank all parties directly and indirectly involved in completing the study, including the Faculty of Administrative Science and Policy Studies, Universiti Teknologi Mara, Kuala Lumpur City Hall and Youth Associations in Kuala Lumpur.

\section{REFERENCES}

[1] R. Sommers and Sundararaman, "Alcohol use among youth," Congressional Research Service, pp.1-2, Library of Congress, 2007.

[2] R. Harker, Statistic on Alcohol, London: House of Commons Library, 2012, pp. 3-6.
[3] K. Park, "Social sciences and medicine," in Preventive and Social Medicine, K. Park, Ed. M/S Banarsidas Bhanot Publishers, Japalpur, 2002.

[4] World Health Report, New Understanding, New Hope, Geneva, 2001

[5] J. Hamalainen, J. Kaprio, E. Isometsä, M. Heikkinen, K. Poikolainen and S. Lindeman, "Cigarette smoking, alcohol intoxication an major depressive episode in a representative population sample," Journal of Epidemiology and Community Health, p. 55, 1996-2001.

[6] National Institute on Alcohol Abuse and Alcoholism, Alcohol-Related Impairment, Alcohol Alert, no. 25, p. 351, 1994.

[7] J. Dorsey, H. Larson, and J. Segal, "Alcohol abuse and alcoholism: Signs, symptoms, effects and testing," Helpguide, vol. 1, no. 1, pp.1-4, 2006.

[8] M. Demmie, M. Gail, and H. Patricia, "The cage questionnaire: Validation of a new alcoholism screening instrument," The American Journal of Psychiatry, vol. 131, no. 10, pp.1121-1123, 1974.

[9] Azizi, Effects of Alcohol Abuse on Human Cognitive, 2000.

[10] U. Sekaran, Research Methods for Business A Skill-Building Approach, $4^{\text {th }}$ ed. John Wiled \& Sons, Inc., 2003.

[11] World Health Organization, Interpersonal Violence and Alcohol, Center for Public Health, 2006

[12] S. Kortteinen, "Negotiating ethnic identities: Alcohol as a Social Marker in East and West Malaysia," Akademika, no. 72, pp. 25-44. 2008.

[13] World Health Organization, Evidence for the Effectiveness and Cost-Effectiveness of Interventions to Reduce Alcohol-Related Harm, Copenhagen, Regional Office for Europe. 2009.

[14] L. M. Powell, J. Williams, and H. Wechsler, "Study habits and the level of alcohol use among college students," Educ. Econ., no. 12, pp. 135-149, 2004.

[15] Alcohol Advisory Council of New Zealand, Annual Report, p. 36, 2012.

[16] National Institute for Health and Care Excellence, "Alcohol-use disorders: diagnosis, assessment and management of harmful drinking and alcohol dependence," 2011

[17] National Institute on Alcohol Abuse and Alcoholism, "Alcohol use and alcohol use disorder in the United States: A 3 year follow up," 2010.

[18] R. A. Singleton, "Collegiate alcohol consumption and academic performance," Journal of Studies on Alcohol and Drugs, vol. 68, no. 4, pp. 548-555, 2007

[19] L. J. Walker, Alcoholism, pp. 1-2, 2003-2004.

[20] J. O'Malley, Alcohol Use among Adolescents, vol. 22, no. 2, 1998.

[21] D. Siemieniako and K. Kubacki, Female Students' Drinking Seen through Collages and Diaries, pp. 297-299, 2013.

[22] Faculty of Public Health, "Alcohol and Public Health," pp. 1-2, 2008.

[23] World Health Organization, Handbook for Action to Reduce Alcohol-Related Harm, Copenhagen, Regional Office for Europe, 2009.

[24] World Health Organization, "Reducing harm from use of alcohol: community responses," New Delhi, WHO Regional Office for South-East Asia, (Alcohol Control Series, No. 5), 2006.

[25] R. Williams and D. C. Vinson, "Validation of a single screening for problem drinking," The Journal of Family Practice, vol. 50, no. 4, pp. 307-312, 2001.

[26] R. N. Parker and L. A. Rebhun, Alcohol and Homicide: A Deadly Combination of Two American Traditions, Albany: State Univ. NY Press, 1995.

[27] J. Langley and K. Kypri, "Secondhand effects of alcohol use on university students," British Medical Journal, no. 327, pp. 1023-1024, 2003.

[28] J. Williams, F. J. Chaloupka, and H. Wechsler, "Are there differential effects of price and policy on college students' drinking intensity?" Nat. Bureau Econ. Res., vol. 1, p. WP 8702, 2002.

[29] E. T. Pascarella, K. M. Goodman, T. A Seifert, G. Tagliapietra-Nicoli, S. Park, and E. J. Whitt, "College student binge drinking and academic achievement: A longitudinal replication and extension," Journal of College Student Development, vol. 48, no. 6, pp. 715-727, 2007.

[30] W. Rau and A. Durand, "The academic ethic and college grades: Does hard work help students to 'Make the grade'?" Sociology of Education, vol. 73, no. 1, pp. 19-38, 2000

[31] H. Wechsler, G. W. Dowdall, G. Maenner, J. Gledhill-Hoyt, and H Lee. "Changes in binge drinking and related problems among American college students between 1993 and 1997: Results of the Harvard School of Public Health College alcohol study," J. Amer. Coll. Hlth, vol. 47, pp. 57-68, 1998.

[32] Alcohol Edu for College National Survey Database, Outside the Classroom, the Impact of Alcohol on Academic Performance, 2008-2009. 
[33] P. M. Kohn and R. G. Smart, "The impact of television advertising on alcohol: an experiment," Journal of Studies on Alcohol, vol. 45, no. 4, pp. 295-330, 1984

[34] R. C. Engs, B. A. Diebold, and D. J. Hanson, "The drinking patterns and problems of a national sample of college students," Journal of Alcohol and Drug Education, vol. 41, no. 3, pp. 13-33, 1996.

[35] S. R. Porter and J. Pryor, "The effects of heavy episodic alcohol use on student engagement, academic performance, and time use," Journal of College Student Development, vol. 48, no. 4, pp. 455-467, 2007.

[36] T. Yamada, K. Michael, and Y. Tadashi, "The impact of alcohol consumption and marijuana use on high school graduation," Health Economics, no. 5, pp. 77-92, 1996.

[37] K. Nordby, G. Reidulf, R. Watten, R. K. Raanaas, and S. Magnussen, "Effects of moderate doses of alcohol on immediate recall of numbers: Some implications for information technology," Journal of Studies on Alcohol, vol. 60, no. 6, pp. 873-878, 1999.

[38] H. Wechsler and T. F. Nelson, "What we have learned from the Harvard School of Public Health College alcohol study: focusing attention on college student alcohol consumption and the environmental conditions that promote it," Journal of Studies on Alcohol and Drugs, pp. 1-10, 2008.

[39] G. E. Wyatt, D. Guthrie, and C. M. Notgrass, "Differential effects of women's child sexual abuse on subsequential sexual revictimization," J Consult Clin Psychol, no. 60, pp. 167-173, 1992.

[40] A. M. Wolaver, "Effects of heavy drinking in college on study effort, grade point average and major choice," Contemporary Economic Policy, vol. 20, no. 4, 2002.

[41] C. A. Preseley, P. W. Meilman, and R. Lyerla, "Alcohol and drugs on American college campuses: Use, consequences, and perceptions of the campus environment," vol. 1, no. 91, pp. 105, 1993

[42] D. Nutbeam, Health Promotion Glossary, Health Promotion International, no. 13, pp. 349-364, 1998.

[43] K. Mäkelä, E. Österberg and P. Sulkunen, "Drink in Finland: increasing alcohol availability in a monopoly state," in Alcohol, Society and State II: The Social History of Control Policy in Seven countries, E. Single, P. Morgan, J. deLint, Eds. Addiction Research Foundation, pp. 31-59, 1981.

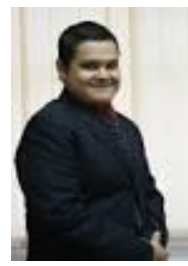

Mohd Ramlan Mohd Arshad is a postgraduate from Faculty of Administrative Science and Policy Studies, Universiti Teknologi Mara Malaysia.

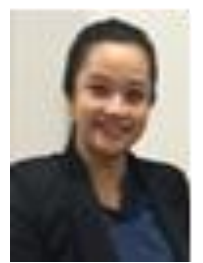

Munirah Omar is currently a graduating student with bachelor administrative science (Hons.) at Faculty of Administrative Science and Policy Studies, Universiti Teknologi Mara Malaysia.

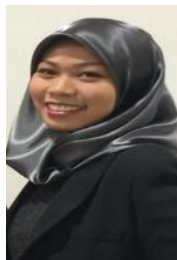

Nurul Afiqah Shahdan is currently a graduating student with bachelor administrative science (Hons.) at Faculty of Administrative Science and Policy Studies, Universiti Teknologi Mara Malaysia. 